\title{
Long-term Follow-Up Results of Dynamic Cervical Implant in Patients with Cervical Disk Diseases: Compared with Arthroplasty
}

\author{
Li Zou ${ }^{1}$ Hao Liu ${ }^{2}$ Xin Rong ${ }^{2}$ Xijiao Liu ${ }^{3}$ Chen Ding ${ }^{2}$ Yueming Song ${ }^{2}$
}

${ }^{1}$ Department of Pediatric Surgery, West China Hospital, Sichuan University, Chengdu, Sichuan Province, People's Republic of China

2 Department of Orthopedics, West China Hospital, Sichuan

University, Chengdu, Sichuan Province, People's Republic of China

${ }^{3}$ Department of Radiology, West China Hospital, Sichuan University, Chengdu, Sichuan Province, People's Republic of China

\author{
Address for correspondence Hao Liu, PhD, MD, 37 Guoxue Lane, \\ Chengdu, Sichuan Province (610041), People's Republic of China \\ (e-mail: liuhao6304@126.com).
}

J Neurol Surg A Cent Eur Neurosurg

\author{
Abstract \\ Keywords \\ - cervical disk \\ degenerative disease \\ - cervical disk \\ replacement \\ - Dynamic Cervical \\ Implant \\ - Arthoplasty
}

Background Arthroplasty has been proven to be a safe and effective treatment for patients with cervical degenerative disk disease (DDD). Dynamic Cervical Implant (DCI) has emerged as a novel implantation device for cervical DDD. This study aimed to compare the outcomes of these procedures after 5 years of follow-up in the $\mathrm{DCl}$ and arthroplastygroups.

Methods This study retrospectively enrolled 79 consecutive cervical DDD patients with $41 \mathrm{DCl}$ and 47 prostheses implanted. Radiographs were analyzed for intervertebral height and range of motion (ROM). Neural function of the patients was assessed using the Neck Disability Index score, visual analog scale, Japanese Orthopaedic Association score and 36-Item Short Form Survey.

Results The $\mathrm{DCl}$ group had statistically lesser flexion/extension and bilateral bending ROM than the arthroplasty group at the operated level(s) $(p<0.05)$. The $\mathrm{DCl}$ group showed improved lordotic alignment of $\mathrm{C} 2-\mathrm{C} 7$ and operated functional spinal unit than arthroplasty group $(p<0.05)$. No statistical difference was observed in the neural function of the two groups. Heterotopic ossification was found in 7 and 14 patients in the $\mathrm{DCl}$ and arthroplasty groups, respectively.

Conclusion The 5-year follow-up results were comparable between the two groups. We believe that $\mathrm{DCl}$ implantation is a safe and effective procedure and could possibly become an alternative treatment for cervical DDD.

\section{Introduction}

Anterior cervical diskectomy and fusion (ACDF) and cervical totaldisk replacement (TDR) are known to be safe and effective in treating patients with cervical degenerative disk disease (DDD) ${ }^{1-3}$ Although symptom relief can be achieved after ACDF, conditions such as decreased range of motion (ROM) and degeneration of adjacent segments are prominently observed. ${ }^{4,5}$ Compared with ACDF, ROM and intradisk pressure at the adjacent levels remain relatively unchanged received

January 24, 2021 accepted after revision November 30, 2021
DOI https://doi.org/ 10.1055/a-1712-5386. ISSN 2193-6315.

\footnotetext{
(C) 2022. The Author(s).

This is an open access article published by Thieme under the terms of the Creative Commons Attribution-NonDerivative-NonCommercial-License, permitting copying and reproduction so long as the original work is given appropriate credit. Contents may not be used for commercial purposes, or adapted, remixed, transformed or built upon. (https://creativecommons.org/ licenses/by-nc-nd/4.0/) Georg Thieme Verlag KG, Rüdigerstraße 14, 70469 Stuttgart, Germany
} 
after TDR, which could contribute to ROM preservation at the target level(s). ${ }^{6,7}$ However, postoperative kyphosis, increased stress on the facet joints, spontaneous fusion, and heterotopic ossification are problems that are encountered after TDR. ${ }^{8}$

Dynamic Cervical Implant (DCI, Paradigm Spine, New York, United States)-a novel $\mathbf{U}$-shaped titanium one-piece nonfusion device-has emerged as a potential solution to problems associated with both ACDF and TDR owing to the fact that it can not only provide controlled flexion and extension but also limit axial rotation and lateral bending, thereby reducing stress on the facet joints. The DCI is also designed to work as a shock absorption device that can protect adjacent levels, and several studies have reported favorable clinical outcomes after DCI implantation. ${ }^{9-11}$ However, evidence comparing outcomes after CDR and DCI is scarce.

Herein, we present the results of 5 years of follow-up among patients with cervical DDD, who underwent either DCI arthroplasty or TDR, and compare the clinical outcomes, radiographic changes, and complications between these two procedures.

\section{Materials and Methods}

This study was approved by the biomedical ethics committee of West China Hospital, Sichuan University. Informed consent was obtained from all the patients so that their data could be used for research purposes.

\section{Patient Selection}

Our study included two cohorts of patients who underwent DCI insertion or TDR with Prestige LP (Medtronic Sofamor Danek, Memphis, Tennessee, United States) between April 2010 and September 2015. The inclusion criteria included age between 18 and 70 years, presence of radiculopathy or myelopathy due to cervical DDD between C3 and C7 that was refractory to conservative therapy for more than 3 months, and a minimum of 5 years of follow-up. The exclusion criteria included presence of active infection, metabolic or systemic disease, rheumatoid arthritis, bony cervical canal stenosis, severe osteoporosis (T score $\leq 2.5$ ), tumors, cervical spondylolisthesis, hyper-reactivity to metal, segmental $\mathrm{ROM}<6$ degrees, and pregnancy. Facet disease was not an absolute contraindication for DCI, but if patients only experienced neck pain without radiculopathy or myelopathy, they did not qualify for surgery.

The DCI group $(n=37)$ consisted of 22 males and 15 females having an average age of 45.6 years (range: 26-66 years) and an average follow-up time of 70.5 months (range: 60-88 months). Preoperative symptoms included radiculopathy in 15 (40\%), myelopathy in 17 (46\%), and combined radiculopathy and myelopathy in 5 (14\%) patients. The TDR group ( $n=42$ ) consisted of 26 males and 16 females having an average age of 44.1 years (range: $25-53$ years) and an average follow-up time of 72.3 months (range: 60-85 months). Preoperative symptoms included radiculopathy in 18 (44\%), myelopathy in 18 (44\%), and combined radiculopathy and myelopathy in $6(12 \%)$ patients.

\section{Surgical Techniques}

\section{The Dynamic Cervical Implant Group}

After establishing anesthesia, the patient was placed in the supine position, with arms at the sides, and the shoulders taped to keep the cervical vertebrae and the head in a neutral extension position. A C-arm fluoroscope was used to determine the surgical level. A 5- to 6-cm transverse incision was made on the right side of the neck. After the index level was exposed with the assistance of the Caspar Cervical Retractor System (Aesculap, Burlingame, California, United States), self-tapping retainer pins were fixed onto the adjacent vertebral bodies and diskectomy was performed using distraction forceps. Although the posterior longitudinal ligament and extruded disk were removed and the osteophytes at the posterior rim of the vertebra were excised, the osteophytes at the anterior rim of the vertebra were seldom dealt with. The cartilaginous endplates were scraped, while the bony endplates were kept intact. Before DCI implantation, the size of the prosthesis that would be appropriate for the procedure was determined using intraoperative C-arm images. Keel cuts were made using the trail as a guide and a keel-cutting chisel. After the DCI prosthesis was inserted, intraoperative $\mathrm{C}$-arm images were obtained to confirm the appropriate size and placement of the implant such that the superior and inferior surfaces of the implant covered the endplate to the maximum extent possible. Care was taken to ensure that the prosthesis was placed in the middle of the intervertebral space, with its anterior and posterior borders more than $3 \mathrm{~mm}$ away from the vertebral body wall.

\section{The Total Disc Replacement Group}

The procedure for Prestige LP placement was similar to that described for $\mathrm{DCI}$, with respect to exposure, diskectomy, and neural decompression. In this procedure, the anterior osteophytes were removed to make the vertebral body wall relatively flat and the endplates were burred to make them parallel and flat, taking care to preserve as much of the cortical endplate as possible. Implant trials were inserted into the disk space to select an appropriate prosthesis. Next, four parallel channels at the upper and lower endplates were made using the rail cutter guide and punch, and finally, the Prestige LP artificial disk was inserted into the disk space.

\section{Clinical Evaluation}

Procedure duration, blood loss, and complications were recorded for both the groups. A comprehensive neurologic examination was performed in all patients preoperatively and at follow-up visits at 3, 6, 12, 24, and 60 months postoperatively. The visual analog scale (VAS) was used to assess neck and arm pain, and neurologic function was evaluated using the Neck Disability Index (NDI) and the Japanese Orthopaedic Association (JOA) score. Odom et al's criteria were employed to evaluate patient satisfaction after surgery. ${ }^{12}$ The eight-dimension 36-Item Short Form Survey 


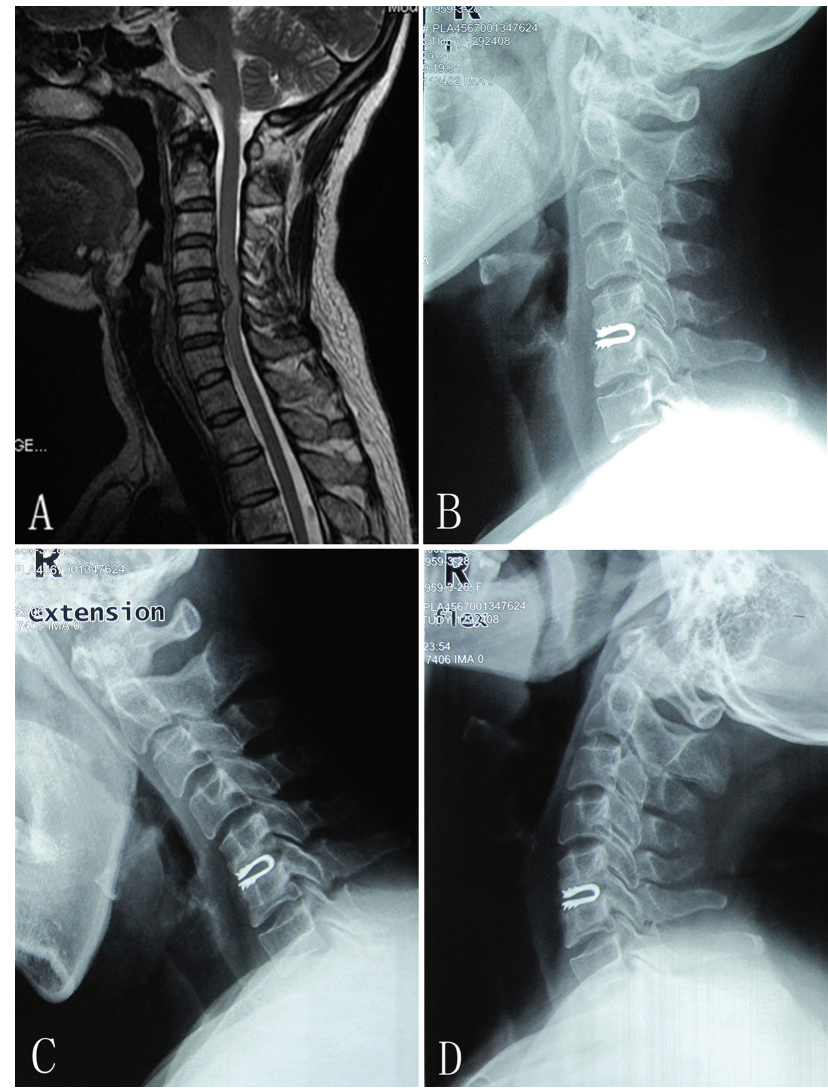

Fig. 1 (A) Preoperative magnetic resonance imaging shows disk herniation at the C5/C6 level. (B-D) Dynamic Cervical Implant implantation at C5/C6 at 60-month follow-up. (B) Neutral lateral radiograph, and segmental range of motion was preserved at (C) flexion and (D) extension.

(SF-36) score (physical function, mental health, bodily pain, vitality, physical role functioning, emotional role functioning, social functioning, and general health) was used to evaluate the quality of life.

\section{Radiographic Analysis}

Anteroposterior, lateral, lateral bending, and flexion-extension cervical spine radiographs, and three-dimensional computed tomography scans in the axial, sagittal, and coronal planes were obtained both preoperatively and at the 3-, 6-, 12-, 24- and 60-month follow-up visits (-Fig. 1). Parameters such as the intervertebral height of the operated segment, alignment of C2-C7, and functional spinal unit (FSU) angle of index levels were measured on neutral lateral radiographs. Flexion-extension and lateral bending radiographs were obtained to determine the ROM of the global cervical spine (C2-C7) at the operated and adjacent levels. All angular ROM values were measured using the Cobb method by utilizing Canvas 11 software (ACD Systems, Seattle, Washington, United States), with the exception of the C2-C7 alignment and FSU angle, which were measured by Harrison's method (-Fig. 2). ${ }^{13}$ All the measurements were independently obtained by L.Z. and X.J.L. who were blinded to patient details. The final values were the average of the two measurements.
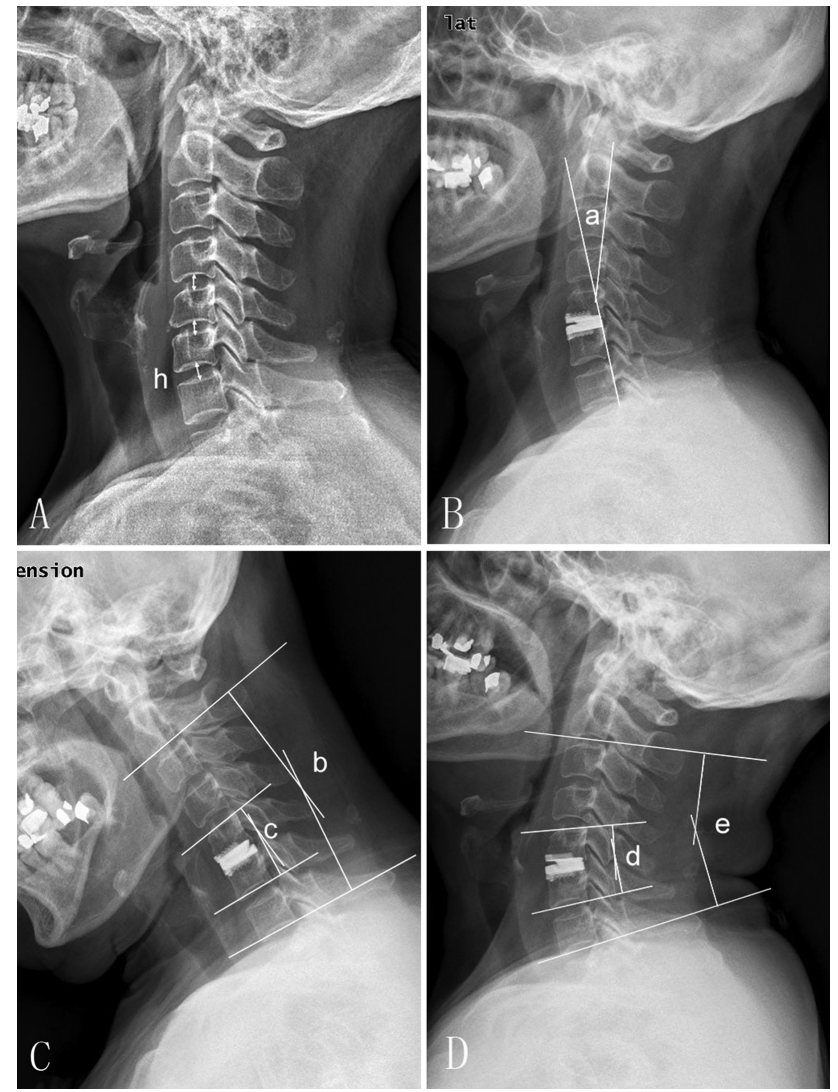

Fig. 2 Radiologic measurements after total disc replacement. (A) Intervertebral height (h) was measured from the midpoints of the upper and lower endplates. (B) Alignment of C2-C7 using Harrison's method. The range of motion of $\mathrm{C} 2-\mathrm{C} 7(\mathrm{~b}+\mathrm{e})$ and operated functional spinal unit $(c+d)$ using Cobb's method on $(C)$ flexion and (D) extension radiograph.

\section{Statistical Analyses}

Continuous data are presented as mean \pm standard deviation, whereas categorical data are presented as numbers and percentages. Between-group differences were assessed using the independent sample $t$-test or the Mann-Whitney $U$ test for continuous variables or using the chi-squared or Fisher's exact test for categorical variables. Intraclass correlation coefficient (ICC) was calculated to evaluate interobserver agreement of radiographic analyses using Cohen's $\mathrm{k}$ statistic. ${ }^{14}$ Kappa values $>0.75$ represented excellent agreement, those between 0.4 and 0.75 represented good agreement, and those below 0.4 represented poor agreement. All statistical analyses were performed using the SPSS software (Version 19, Chicago, Illinois, United States). All analyses of statistical significance were two sided, and significance was set at $p<0.05$.

\section{Results}

\section{Clinical Outcomes}

Of the 37 patients in the DCI group, 33 received single-level DCI implantation and 4 received double-level DCI implantation. Of the 42 patients in the Prestige LP group, those who received single-level prosthesis implantation and those who received double-level prostheses implantation were 37 and 
Long-Term Follow-Up Results of DCI in Patients with DDD Zou et al.

Table 1 Summary of neck and arm visual analog scale (CAS) scores, preoperatively and at 5-year follow-up intervals, in the two groups

\begin{tabular}{|l|l|l|l|l|}
\hline & \multicolumn{2}{|l|}{ Neck VAS } & \multicolumn{2}{l|}{ Arm VAS } \\
\hline & DCI & TDR & DCI & TDR \\
\hline Pre-op & $6.0 \pm 2.2$ & $6.6 \pm 2.3$ & $6.5 \pm 1.6$ & $6.4 \pm 1.7$ \\
\hline 3 -mo & $2.0 \pm 0.6$ & $1.9 \pm 0.8$ & $1.9 \pm 0.8$ & $2.0 \pm 0.9$ \\
\hline 6 -mo & $1.8 \pm 0.5$ & $1.8 \pm 0.6$ & $1.8 \pm 0.6$ & $1.8 \pm 0.4$ \\
\hline 12 -mo & $1.9 \pm 0.7$ & $1.8 \pm 0.7$ & $1.6 \pm 0.8$ & $1.9 \pm 0.7$ \\
\hline $24-$ mo & $1.9 \pm 0.5$ & $1.7 \pm 0.6$ & $1.8 \pm 0.9$ & $1.7 \pm 0.7$ \\
\hline $60-$ mo & $1.8 \pm 0.5$ & $1.6 \pm 0.5$ & $1.7 \pm 0.7$ & $1.8 \pm 0.8$ \\
\hline
\end{tabular}

Abbreviation: DCI, Dynamic Cervical Implant; TDR: total disc replacement.

5 , respectively. No statistical difference was noted in the neck and arm VAS (-Table 1), NDI, JOA, or SF-36 scores between the two groups before surgery, postoperatively, or during the follow-up period ( $p>0.05$ for all; - Table 2 ). In contrast, neck and arm VAS, JOA, NDI, and SF-36 scores showed significant improvement after surgery in both groups of patients, and this effect lasted throughout the 60-month follow-up $(p<0.05)$. NDI success rate, defined as $\geq 15$ point improvement in NDI at the 60-month follow-up, was 92.5 and $88.9 \%$ in the DCI and Prestige LP groups, respectively. Compared with the scores before surgery, all eight dimension subscores of the SF-36 showed improvement at each follow-up $(p<0.05)$. Neural improvement based on Odom's criteria was distributed as follows: 22 (59.1\%) patients reported excellent, 12 (31.8\%) as good, and $3(9.1 \%)$ fair outcome in the DCI group; these values were 26 (63.0\%), 12 (29.6\%), and 4 (7.4\%), respectively, in the TDR group.

\section{Radiographic Outcomes}

At the final follow-up, intervertebral height at the operated level increased significantly from $4.4 \pm 1.2 \mathrm{~mm}$ preoperatively to $5.0 \pm 1.7 \mathrm{~mm}$ in the DCI group and from $4.6 \pm 1.3 \mathrm{~mm}$ preoperatively to $5.6 \pm 1.8 \mathrm{~mm}$ postoperatively in the TDR group ( $p<0.05$ for all). Both groups showed comparable intervertebral height restoration after surgery. In the DCI group, FSU ROM at the treated level decreased mildly from
$9.1 \pm 3.1$ degrees preoperatively to $8.2 \pm 2.6$ degrees at the final follow-up ( $p>0.05)$, whereas it increased slightly from $8.8 \pm 2.9$ to $10.2 \pm 3.4$ degrees in the TDR group $(p>0.05)$. Thus, TDR patients showed greater FSU ROM than DCI patients at the 60-month follow-up, although the values were comparable preoperatively $(p>0.05)$. Compared with the preoperative values, there was no significant increase in the upper and lower adjacent level ROM in either group at the final follow-up $(p>0.05)$. Cervical alignment at C2-C7 and the FSU angle in the DCI group showed a significant increase in lordosis $(p<0.05$; - Fig. 3), whereas these values remained at preoperative levels in the TDR group $(p>0.05)$. At the final follow-up, FSU left and right lateral bending ROMs decreased significantly to a small extent, from preoperative levels in the DCI group $(p<0.05)$, whereas they were unaltered in the TDR group $(p>0.05)$. Furthermore, at the final follow-up, the TDR group had larger FSU left and right lateral bending ROMs than the DCI group $(p<0.05 ;$ - Table 3). ICC $\mathrm{k}$ values between L.Z. and X.J.L. for radiology analyses were 0.922 , indicating excellent agreement.

\section{Complications}

No severe complications were observed in either of the groups, except for mild dysphagia in the early postoperative period in four (10.8\%) patients in the DCI group and in five

Table 2 Eight dimensions of 36-Item Short Form Survey (SF-36), preoperatively and at 60 months of follow-up, in the two groups

\begin{tabular}{|l|l|l|l|l|l|l|}
\hline \multirow{2}{*}{} & \multicolumn{2}{|l|}{ Pre-op } & & 60 mo & \multicolumn{2}{l|}{} \\
\cline { 2 - 7 } & DCI & TDR & $p$ value & DCI & TDR & $p$ value \\
\hline Physical function & $53.2 \pm 21.7$ & $51.6 \pm 18.7$ & 0.385 & $82.3 \pm 21.3$ & $78.5 \pm 28.7$ & 0.082 \\
\hline Role-physical & $48.6 \pm 19.2$ & $45.3 \pm 18.4$ & 0.279 & $67.2 \pm 18.6$ & $68.6 \pm 23.4$ & 0.763 \\
\hline Bodily pain & $38.9 \pm 13.6$ & $41.5 \pm 14.2$ & 0.097 & $68.3 \pm 20.4$ & $70.5 \pm 22.1$ & 0.481 \\
\hline General health & $40.2 \pm 14.3$ & $43.1 \pm 19.5$ & 0.086 & $69.3 \pm 24.5$ & $72.7 \pm 23.0$ & 0.092 \\
\hline Vitality & $49.1 \pm 19.7$ & $51.9 \pm 20.3$ & 0.134 & $69.4 \pm 21.5$ & $69.1 \pm 18.7$ & 0.837 \\
\hline Social function & $57.9 \pm 20.1$ & $55.3 \pm 24.5$ & 0.235 & $80.4 \pm 21.7$ & $77.9 \pm 21.8$ & 0.583 \\
\hline Role-emotional & $36.4 \pm 12.5$ & $38.9 \pm 15.0$ & 0.525 & $79.7 \pm 15.4$ & $76.4 \pm 19.8$ & 0.387 \\
\hline Mental health & $60.9 \pm 18.0$ & $57.2 \pm 16.7$ & 0.384 & $83.4 \pm 24.1$ & $80.9 \pm 25.3$ & 0.632 \\
\hline
\end{tabular}

Abbreviation: DCI, Dynamic Cervical Implant TDR: total disc replacement. 


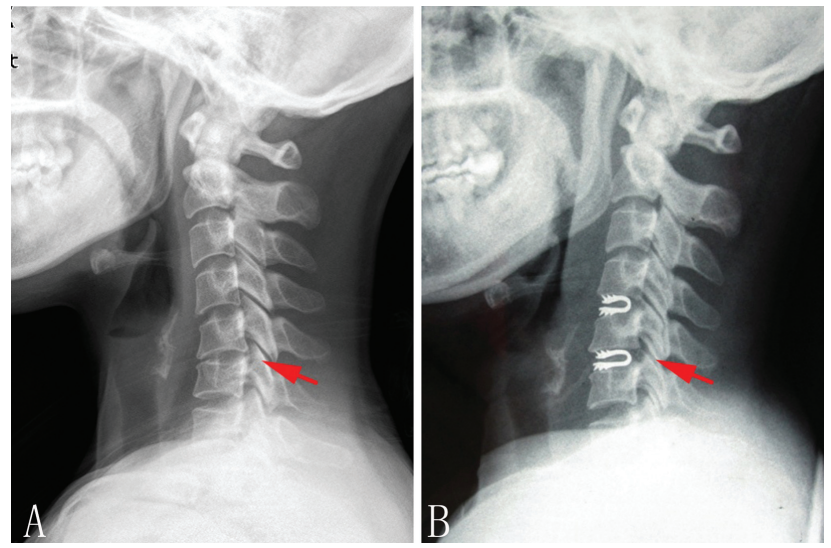

Fig. 3 (A) Kyphosis at C2-C7 and C5/C6 preoperatively (red arrow). (B) The alignment of $\mathrm{C2}-\mathrm{C} 7$ and functional spinal unit angle restored lordosis at $\mathrm{C5} /$ C6 at 60 months after Dynamic Cervical Implant implantation (red arrow).

(11.9\%) patients in the TDR group. Importantly, these symptoms disappeared spontaneously during a period of several days to weeks. At the final follow-up, 7 (18.9\%) patients in the DCI group and $14(33.3 \%)$ in the TDR group were found to have heterotopic ossification (-Fig. 4), and this incidence was higher in the TDR group than in the DCI group $(p<0.05 ;$ - Table 4$)$.

\section{Discussion}

Numerous studies have reported equivalent or better clinical outcomes in patients after TDR compared with ACDF, although the latter is regarded as the gold standard for surgical treatment of cervical DDD. ${ }^{15,16}$ In a prospective study conducted by Peng et $\mathrm{al}^{6}$ including 40 patients (59 prostheses) with Prestige LP disk replacement, neck and arm VAS, NDI, JOA, and SF-36 scores were found to have significantly improved after a minimum 2 years of follow-up, compared with the preoperative values. However, no significant differ-
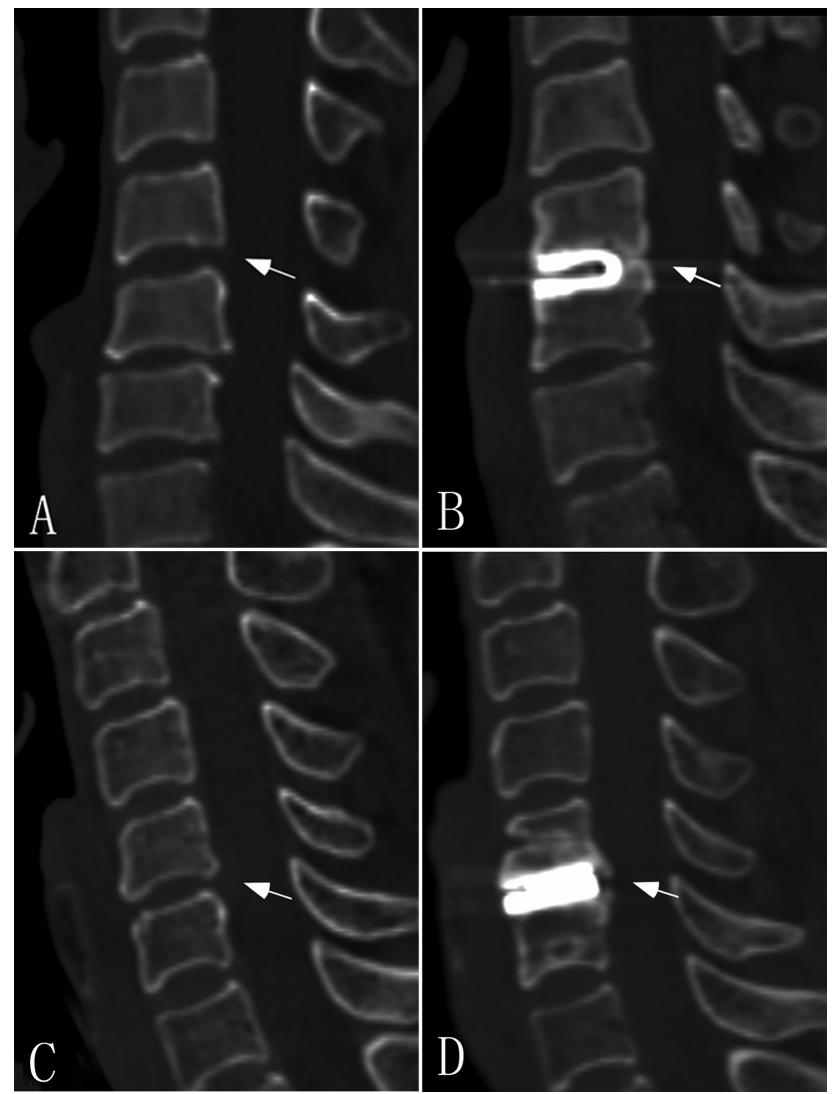

Fig. 4 (A) There was no obvious osteophyte noted at the C5/C6 level. (B) Forty-eight months after Dynamic Cervical Implant implantation at the same level, heterotopic ossification $(\mathrm{HO})$ was observed (white arrow). (C) There was no obvious osteophyte noted at the C5/C6 level; (D) Twenty-four months after TDR at the same level, HO formation was observed (white arrow).

ences were observed between the Prestige LP and ACDF groups.

DCI is a novel nonfusion treatment approach for cervical DDD, wherein anterior neural decompression obtained is

Table 3 Radiographic results, preoperatively and at 60 months of follow-up $\left(^{\circ}\right)$, for the two groups

\begin{tabular}{|l|l|l|l|l|l|l|}
\hline & \multicolumn{2}{|l|}{ Pre-op } & & $60 \mathrm{mo}$ & \\
\cline { 2 - 7 } & DCI & TDR & $p$ value & DCl & TDR & $p$ value \\
\hline C2-C7 & $50.0 \pm 14.8$ & $53.4 \pm 15.6$ & 0.176 & $49.8 \pm 13.5$ & $54.9 \pm 17.3$ & 0.082 \\
\hline operated level & $9.1 \pm 3.1$ & $8.8 \pm 2.9$ & 0.312 & $8.2 \pm 2.6$ & $10.2 \pm 3.4$ & $0.023^{\mathrm{a}}$ \\
\hline upper adjacent level & $9.4 \pm 4.2$ & $9.2 \pm 4.8$ & 0.099 & $9.2 \pm 3.0$ & $8.4 \pm 2.9$ & 0.081 \\
\hline lower adjacent level & $8.4 \pm 3.6$ & $9.0 \pm 3.7$ & 0.124 & $8.9 \pm 2.9$ & $7.8 \pm 2.6$ & 0.236 \\
\hline C2-C7 left lateral bending & $28.9 \pm 9.8$ & $30.4 \pm 9.4$ & 0.063 & $26.7 \pm 8.3$ & $32.4 \pm 9.5$ & 0.521 \\
\hline C2-C7 right lateral bending & $30.5 \pm 10.3$ & $29.7 \pm 9.0$ & 0.391 & $26.9 \pm 7.9$ & $31.4 \pm 8.7$ & 0.929 \\
\hline FSU left lateral bending & $3.5 \pm 1.6$ & $3.4 \pm 1.4$ & 0.382 & $1.1 \pm 0.3$ & $3.9 \pm 1.5$ & $0.000^{\mathrm{a}}$ \\
\hline FSU right lateral bending & $3.4 \pm 1.6$ & $3.6 \pm 1.5$ & 0.679 & $1.2 \pm 0.2$ & $3.8 \pm 1.7$ & $0.000^{\mathrm{a}}$ \\
\hline C2-C7 alignment & $10.5 \pm 9.5$ & $11.9 \pm 9.8$ & 0.071 & $16.7 \pm 7.8$ & $12.9 \pm 9.2$ & 0.032 \\
\hline FSU angle & $2.3 \pm 3.6$ & $2.5 \pm 4.9$ & 0.187 & $5.7 \pm 4.8$ & $2.7 \pm 3.3$ & $0.020^{\mathrm{a}}$ \\
\hline intervertebral height (mm) & $4.4 \pm 1.2$ & $4.6 \pm 1.3$ & 0.341 & $5.0 \pm 1.7$ & $5.6 \pm 1.8$ & 0.102 \\
\hline
\end{tabular}

Abbreviations: DCI, Dynamic Cervical Implant; FSU, functional spinal unit; Pre-op, preoperation TDR: total disc replacement.

${ }^{\text {a}}$ Statistical significance. 
Table 4 Summary of demographic, surgical data and complications in the two groups

\begin{tabular}{|c|c|c|c|}
\hline & DCI group & TDR group & $p$ value \\
\hline$N$ & 37 & 42 & \\
\hline age $(y)$ & 45.6 & 44.1 & 0.382 \\
\hline male (\%) & 59.5 & 61.9 & 0.571 \\
\hline \multicolumn{4}{|l|}{ Symptoms } \\
\hline radiculopathy & 15 & 18 & 0.327 \\
\hline myelopathy & 17 & 18 & 0.649 \\
\hline both & 5 & 6 & 0.540 \\
\hline \multicolumn{4}{|l|}{ Implanted level } \\
\hline $\mathrm{C} 3 / \mathrm{C} 4$ & 3 & 3 & 0.356 \\
\hline $\mathrm{C} 4 / \mathrm{C5}$ & 6 & 7 & 0.671 \\
\hline $\mathrm{C} 5 / \mathrm{C6}$ & 26 & 28 & 0.238 \\
\hline $\mathrm{C6} / \mathrm{C7}$ & 6 & 9 & 0.832 \\
\hline \multicolumn{4}{|c|}{ Operation duration (min) } \\
\hline single level & 95 & 100 & 0.272 \\
\hline double level & 133 & 145 & 0.098 \\
\hline \multicolumn{4}{|l|}{ Blood loss (ml) } \\
\hline single level & 70 & 82 & 0.322 \\
\hline double level & 100 & 120 & 0.763 \\
\hline \multicolumn{4}{|l|}{ Complications } \\
\hline dysphagia & $4(10.8 \%)$ & $5(11.9 \%)$ & 0.467 \\
\hline $\mathrm{HO}$ & 7 (18.9\%) & $14(33.3 \%)$ & $0.023^{\mathrm{a}}$ \\
\hline
\end{tabular}

Abbreviations: DCl, Dynamic Cervical Implant; HO, heterotopic ossification TDR: total disc replacement.

${ }^{\text {a}}$ Statistical significance.

similar to that achieved with TDR. In addition, recent reports have demonstrated the safety and efficacy of DCI replacement, and these are comparable with clinical outcomes at early-medium follow-up after TDR. Wang et al ${ }^{11}$ conducted a prospective study in 30 patients undergoing single-level DCI implantation and reported that the average scores of JOA, VAS, NDI, and SF-36 improved significantly at 24 months of follow-up. We also reported a comparable improvement in NDI, VAS, JOA, and SF-36 scores in the DCI and TDR groups, which was a result of complete neural decompression, and, importantly, our results concur with those of other reports. With respect to Odom's criteria, $90.9 \%$ in the DCI group and 92.6\% patients in the TDR group showed excellent and good outcomes, respectively. No statistical difference was observed between the two groups in terms of excellent or good outcomes because of the same neural decompression process conducted in the two groups. Thus, as DCI results in good neural decompression and pain relief, it could be a viable alternative to TDR or ACDF.

Recently, preserving segmental motion and preventing degeneration of adjacent segments have gained attention. The prosthesis is designed to mimic the biomechanical function of a normal disk, and the superiority of TDR has been widely reported. Quan et $\mathrm{al}^{17}$ conducted a long-term follow-up study to investigate clinical and radiologic outcomes after cervical arthroplasty, and they report that, at final follow-up, an average ROM of $8.4 \pm 5.8$ degrees (range: 0-20.6 degrees) was preserved at the surgically treated segment, whereas no increase was observed in the ROM of the adjacent upper and lower segments. The $\mathbf{U}$-shaped DCI device is designed to enable controlled motion at the index level and thus does not alter ROM at the adjacent levels. Similarly, a recent study in 53 patients with cervical DDD who underwent DCI replacement revealed that ROM at the index level was preserved at 5.3 degrees at 24 months of follow-up, and the ROMs were slightly decreased at the adjacent upper and lower segments. ${ }^{9}$ Thus, it appears that motion preservation by the prosthesis had compensated for adjacent segments.

Although TDR has been shown to be successful with respect to motion preservation at the index level and protecting adjacent levels, recent studies have also highlighted potential limitations of TDR. ${ }^{18-20}$ For instance, the prosthesis altered the biomechanics at the surgically treated level, which resulted in greater strain on the facet joints, uncovertebral joints, and ligaments. Kang et $\mathrm{al}^{20}{ }^{20}$ in an in vivo image-based finite element study of outcomes after the implantation of the Bryan, Prestige LP, or ProDisc-C cervical disk prosthesis, found that the Bryan prosthesis imposed the greatest stress on the facet and uncovertebral joints with flexion-extension and all three prostheses led to higher loads at the joints upon lateral bending. In contrast to TDR, DCI can facilitate controlled motion during flexion-extension and limit bilateral bending and rotation at the operated level, which is theoretically expected to reduce strain on the facet joints and ligaments at the index level(s). This phenomenon can protect facet joints at the index level(s), especially in the presence of facet joint disease. Welke et $\mathrm{al}^{7}$ conducted an in vitro study with single-level dynamic stabilization in DCI, TDR, or simulated ACDF, and showed that DCI had a milder effect on adjacent levels than ACDF; furthermore, the decrease in ROM during flexion-extension and lateral bending may provide protection against facet joint arthritis, which is a contraindication for TDR.

We showed that ROM at the operated level in the DCI group was maintained at 8.2 degrees at the final follow-up, which was not significantly different from a preoperative value of 9.1 degrees. However, in the Prestige LP group, the ROM of FSU was 10.2 degrees at the final follow-up and was greater than that of the DCI group. This result can be attributed to the motion-controlled design of the DCI implant. Similarly, FSU left and right lateral bending ROMs were significantly lesser in the DCI group than in the TDR group. Notably, as the primary motion style of the subaxial cervical spine is flexion and extension, any decrease in the segmental lateral bending will have an indiscernible influence on the total cervical ROM.

Another important issue to which attention should be paid is sagittal malalignment of the cervical spine after TDR, particularly kyphosis. Pickett et $\mathrm{al}^{18}$ analyzed radiographic outcomes in 14 patients who had undergone TDR, and at an 
average follow-up of 12.4 months, they found that the mean shell and FSU angle showed significant kyphosis compared with preoperative lordosis. However, other studies did not find sagittal malalignment after TDR; for example, Park et $\mathrm{al}^{21}$ investigated the kinematics of four types of cervical disk prostheses and reported that sagittal lordosis increased and index lordosis was maintained at final follow-up. As for the $\mathbf{U}$-shaped novel design of $\mathrm{DCI}$, some reports have described an improvement in lordosis at cervical, sagittal, and index levels. ${ }^{16}$ In our study, despite being comparable at the C2-C7 alignment and FSU angles before surgery, the DCI group showed significant improvement in lordotic alignment at both C2-C7 and FSU at the final follow-up compared with preoperative or corresponding values in the TDR group; in contrast, lordosis of $\mathrm{C} 2-\mathrm{C} 7$ and FSU was preserved in the Prestige LP group.

Our study has some limitations. First, the sample size was small. Our study was designed to compare outcomes after 5 years of follow-up after DCI or Prestige LP arthroplasty, and some patients were lost to follow-up. Second, this was a single-center study. However, all surgeries were performed by two surgeons who followed identical procedures. Moreover, all TDR implantations were performed by one surgeon (HL); thus, bias by different operative skills was limited.

\section{Conclusion}

Five-year follow-up results were comparable between DCI and Prestige LP in patients with cervical DDD. We believe that DCI implantation is a safe and effective procedure that can be an alternate choice for the treatment of DDD in the future.

\section{Conflict of Interest}

None declared.

\section{References}

1 Bohlman HH, Emery SE, Goodfellow DB, Jones PK. Robinson anterior cervical discectomy and arthrodesis for cervical radiculopathy. Long-term follow-up of one hundred and twenty-two patients. J Bone Joint Surg Am 1993;75(09):1298-1307

2 Boody BS, Lee EN, Sasso WR, et al. Functional outcomes associated with adjacent-level ossification disease 10 years after cervical disc arthroplasty or ACDF. Clin Spine Surg 2020;33(09): E420-E425

3 Tomé-Bermejo F, Morales-Valencia JA, Moreno-Pérez J, et al. Degenerative cervical disc disease: Long-term changes in sagittal alignment and their clinical implications after cervical interbody fusion cage subsidence: a prospective study with standalone lordotic tantalum cages. Clin Spine Surg 2017;30(05):E648-E655

4 Wigfield C, Gill S, Nelson R, Langdon I, Metcalf N, Robertson J. Influence of an artificial cervical joint compared with fusion on adjacent-level motion in the treatment of degenerative cervical disc disease. J Neurosurg 2002;96(1, Suppl):17-21
5 Matsunaga S, Kabayama S, Yamamoto T, Yone K, Sakou T, Nakanishi K. Strain on intervertebral discs after anterior cervical decompression and fusion. Spine 1999;24(07):670-675

6 Peng CW, Yue WM, Basit A, et al. Intermediate results of the Prestige LP cervical disc replacement: clinical and radiological analysis with minimum two-year follow-up. Spine 2011;36(02): E105-E111

7 Welke B, Schwarze M, Hurschler C, Book T, Magdu S, Daentzer D. In vitro investigation of a new Dynamic Cervical Implant: comparison to spinal fusion and total disc replacement. Eur Spine J 2016;25(07):2247-2254

8 Zeng J, Liu H, Chen $\mathrm{H}$, et al. Comparison of heterotopic ossification after fixed- and mobile-core cervical disc arthroplasty. World Neurosurg 2018;120:e1319-e1324

9 Matgé G, Berthold C, Gunness VR, Hana A, Hertel F. Stabilization with the Dynamic Cervical Implant: a novel treatment approach following cervical discectomy and decompression. J Neurosurg Spine 2015;22(03):237-245

10 Shichang L, Yueming S, Limin L, et al. Clinical and radiologic comparison of Dynamic Cervical Implant arthroplasty and cervical total disc replacement for single-level cervical degenerative disc disease. J Clin Neurosci 2016;27:102-109

11 Wang L, Song YM, Liu LM, Liu H, Li T. Clinical and radiographic outcomes of Dynamic Cervical Implant replacement for treatment of single-level degenerative cervical disc disease: a 24month follow-up. Eur Spine J 2014;23(08):1680-1687

12 Odom GL, Finney W, Woodhall B. Cervical disk lesions. J Am Med Assoc 1958;166(01):23-28

13 Harrison DE, Harrison DD, Cailliet R, Troyanovich SJ, Janik TJ, Holland B. Cobb method or Harrison posterior tangent method: which to choose for lateral cervical radiographic analysis. Spine 2000;25(16):2072-2078

14 Landis JR, Koch GG. The measurement of observer agreement for categorical data. Biometrics 1977;33(01):159-174

15 Goffin J, Casey A, Kehr P, et al. Preliminary clinical experience with the Bryan cervical disc prosthesis. Neurosurgery 2002;51(03): 840-845, discussion 845-847

16 Garrido BJ, Taha TA, Sasso RC. Clinical outcomes of Bryan cervical disc arthroplasty a prospective, randomized, controlled, single site trial with 48-month follow-up. J Spinal Disord Tech 2010;23 (06):367-371

17 Quan GM, Vital JM, Hansen S, Pointillart V. Eight-year clinical and radiological follow-up of the Bryan cervical disc arthroplasty. Spine 2011;36(08):639-646

18 Pickett GE, Mitsis DK, Sekhon LH, Sears WR, Duggal N. Effects of a cervical disc prosthesis on segmental and cervical spine alignment. Neurosurg Focus 2004;17(03):E5

19 Lee SH, Im YJ, Kim KT, Kim YH, Park WM, Kim K. Comparison of cervical spine biomechanics after fixed- and mobile-core artificial disc replacement: a finite element analysis. Spine 2011;36(09): 700-708

20 Kang H, Park P, La Marca F, Hollister SJ, Lin CY. Analysis of load sharing on uncovertebral and facet joints at the C5-6 level with implantation of the Bryan, Prestige LP, or ProDisc-C cervical disc prosthesis: an in vivo image-based finite element study. Neurosurg Focus 2010;28(06):E9

21 Park SB, Kim KJ, Jin YJ, Kim HJ, Jahng TA, Chung CK. X-ray-based kinematic analysis of cervical spine according to prosthesis designs: analysis of the Mobi C, Bryan, PCM, and Prestige LP. J Spinal Disord Tech 2015;28(05):E291-E297 